\title{
Correction to: Honey protects against chronic unpredictable mild stress induced- intestinal barrier disintegration and hepatic inflammation
}

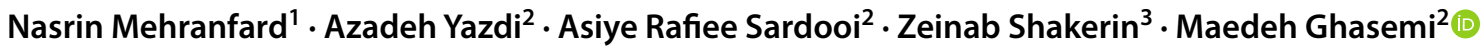

Published online: 24 March 2021

(c) Springer Nature B.V. 2021

\section{Correction to: \\ Molecular Biology Reports (2020) 47:8475-8484 \\ https://doi.org/10.1007/s11033-020-05888-4}

The correct spelling of the 3rd author's name is Asiye Rafiee Sardooi.

The original article has been corrected.

Publisher's Note Springer Nature remains neutral with regard to jurisdictional claims in published maps and institutional affiliations.

The original article can be found online at https://doi.org/10.1007/ s11033-020-05888-4.

Maedeh Ghasemi

ghasemi.m@med.mui.ac.ir

1 Neurophysiology Research Center, Cellular and Molecular Medicine Institute, Urmia University of Medical Sciences,

Urmia, Iran

2 Department of Physiology, School of Medicine, Isfahan University of Medical Sciences, Isfahan, Iran

$3 \mathrm{PhD}$ of Anatomical Science, Department of Anatomy, School of Medicine, Isfahan University of Medical Sciences, Isfahan, Iran 